\title{
Our time around the lake: a hiking tour historical geology group project
}

\section{Erik Haroldson}

Department of Geosciences, Austin Peay State University, Clarksville, TN, 37044
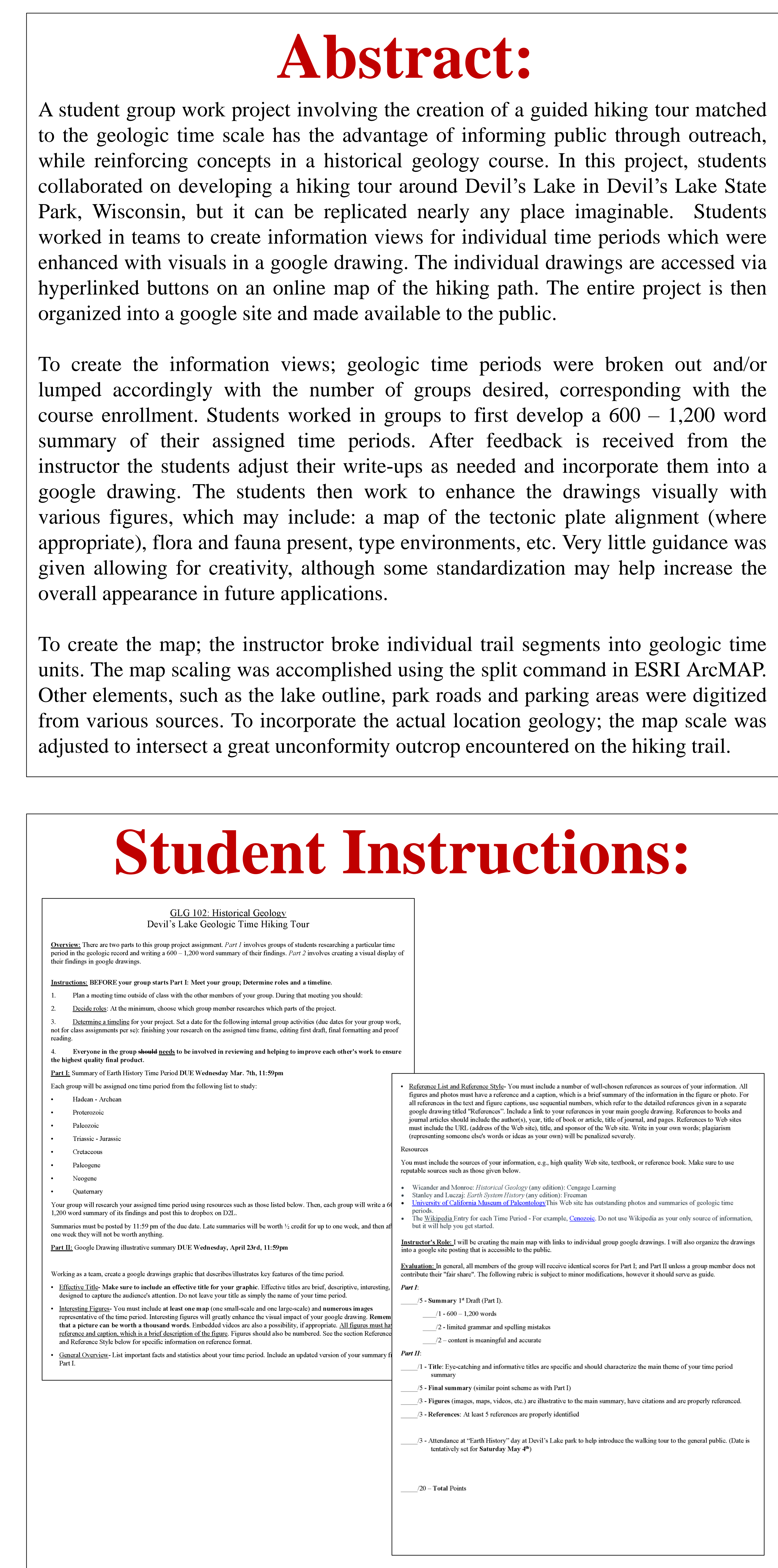

Acknowledgements:

\section{GJ Baraboo Sauk County}

This project was developed and trialed while I was an associate lecturer at the University of Wisconsin-Baraboo/Sauk County. I am grateful to the participation

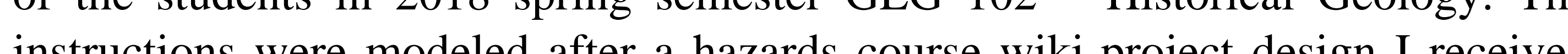
from Dr. Jacalyn Malinowski (SUNY-Geneseo).

\section{Instructor Created Content:}
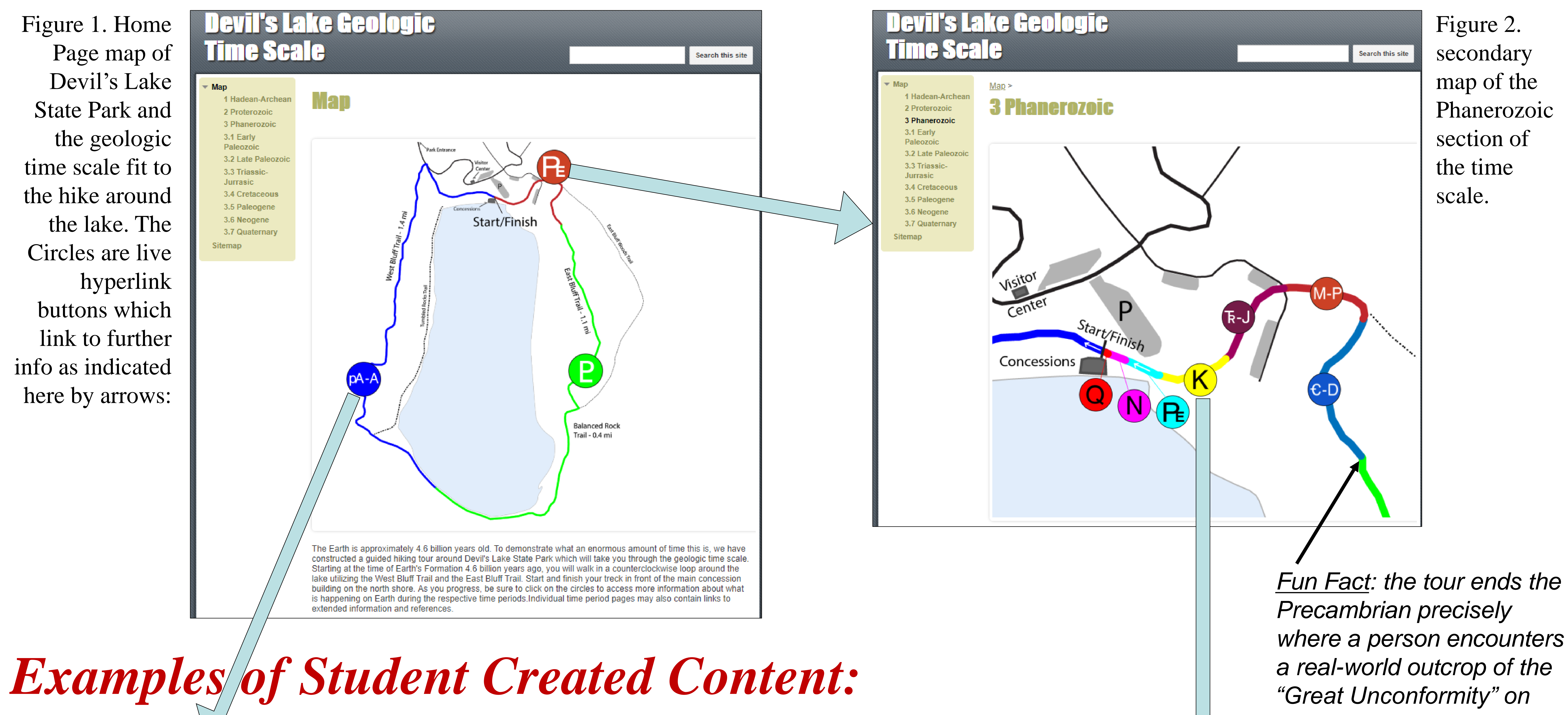
Precambrian precisely where a person encounters a real-world outcrop of the "Great Unconformity" on the trail.
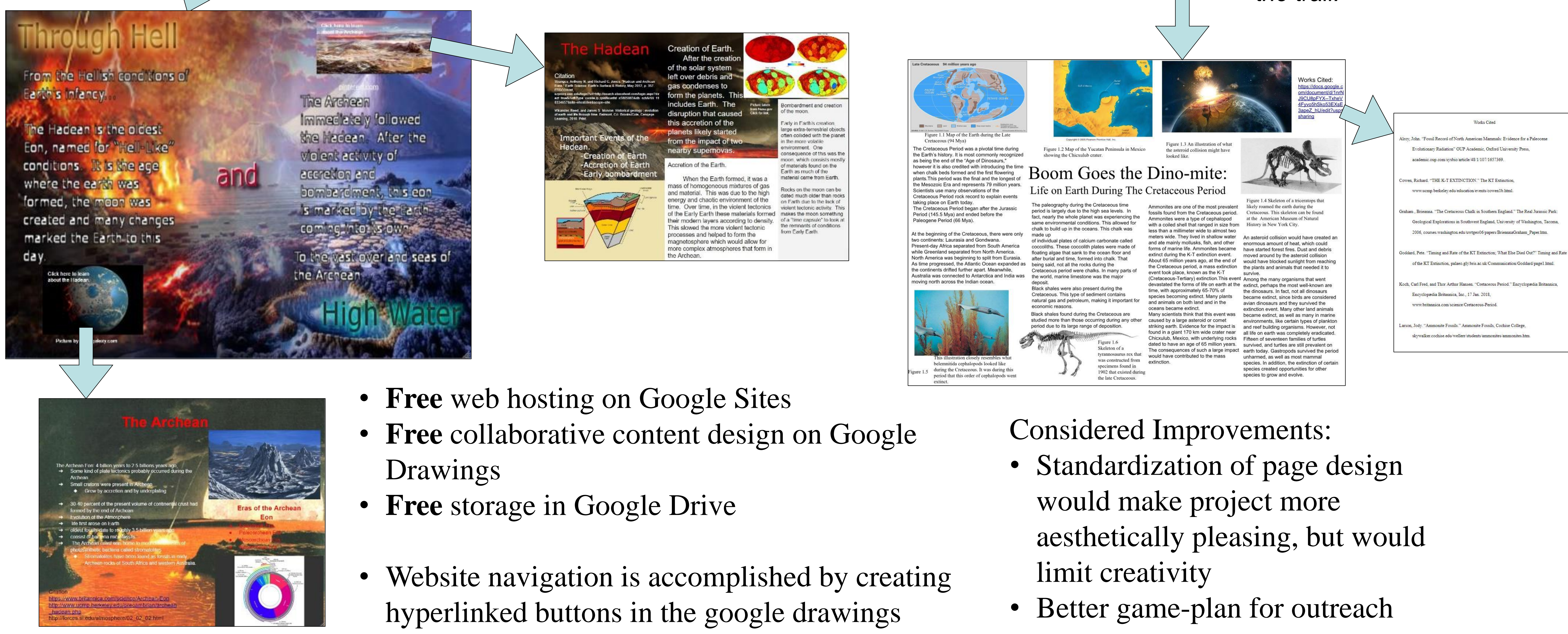

web hosting on Google Sites

Free collaborative content design on Google Drawings

- Free storage in Google Drive

- Website navigation is accomplished by creating hyperlinked buttons in the google drawings

- Standardization of page design would make project more aesthetically pleasing, but would limit creativity

- Better game-plan for outreach

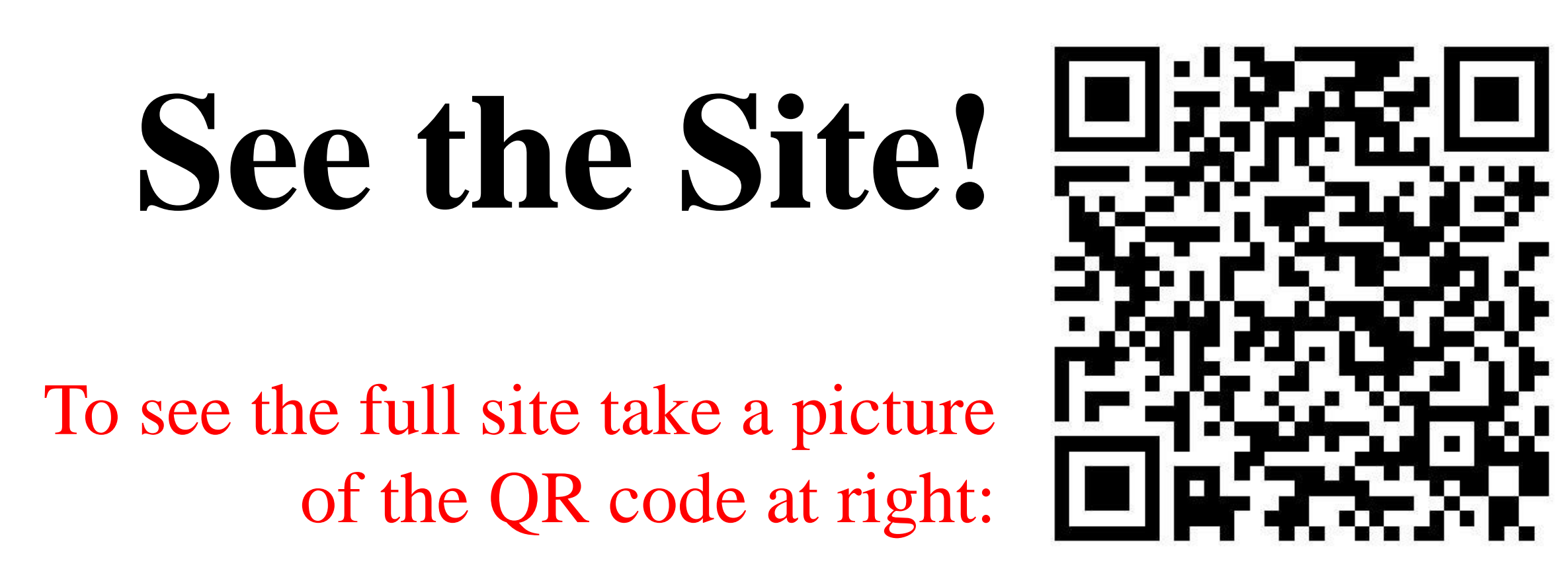

Now a SERC Activity!

Science Education Resource Center (SERC) "Teach the Earth" Activities Collection: 